\title{
O USO DE FILMES PARA OBTER COMPREENSÓES SOBRE A PRÁTICA PEDAGÓGICA EM EDUCAÇÃO INFANTIL: DUAS ABORDAGENS METODOLÓGICAS
}

\author{
ThE USE OF FILMS TO OBTAIN UNDERSTANDINGS ON \\ PEDAGOGICAL PRACTICE IN EARLY CHILDHOOD EDUCATION: \\ TWO METHODOLOGICAL APPROACHES
}

\begin{abstract}
Lenira Haddad
Doutorado em Educaçáo pela Faculdade de Educaçáo da Universidade de São Paulo. Docente na Universidade Federal de Alagoas, Centro de Educação. Maceio, AL - Brasil ORCID: http://orcid.org/0000-0002-3588-2846 lenirahaddad@gmail.com
\end{abstract}

\begin{abstract}
Resumo: Este artigo apresenta duas abordagens metodológicas de pesquisa qualitativa que utilizam filmes para obter compreensôes sobre a prática pedagógica em educação infantil. Uma refere-se à etnografia visual e multivocal desenvolvida por Tobin e colaboradores, que deu origem à clássica obra Educação infantil em três culturas: Japão, China e Estados Unidos (2008); outra, menos conhecida, trata-se do SOPHOS, acrônimo para Second Order Phenomenological Observation Scheme - Esquema de Observação Fenomenológica de Segunda Ordem, desenvolvida e testada por duas dinamarquesas: Hensen e Jensen (2004) para uma pesquisa transnacional europeia retratada em livro de Cameron e Moss (2007). Embora SOPHOS se inspire na pesquisa de Tobin, apresenta diferenças substantivas quanto aos objetivos perseguidos. Essas diferenças e suas implicaçóes epistemológicas e metodológicas são discutidas e ilustradas por meio da descrição das respectivas pesquisas.
\end{abstract}

Palavras-Chave: Educação Infantil; Etnografia Visual e Multivocal; Filmes; Práticas Pedagógicas; Sophos; Tobin.

Aвstract: This article presents two methodological approaches to qualitative research that use films to obtain insights about the pedagogical practice of early childhood education. One refers to visual and multivocal ethnography developed by Tobin and colleagues, which gave rise to the classic work Pre-school in three cultures: Japan, China and the United States (1989); other, less well-known, is SOPHOS, an acronym for the Second Order Phenomenological Observation Scheme, developed and tested by two Danes: Hensen and Jensen (2004) for a European transnational research portrayed in a 
book by Cameron and Moss (2007). Although SOPHOS is inspired by Tobin's research, it presents substantive differences as to the objectives pursued. These differences and their epistemological and methodological implications are discussed and illustrated through the description of their research.

KeYwords: Early Childhood Education; Visual and Multivocal Ethnography; Films; Pedagogical Practices; Sophos; Tobin.

\section{Introdução}

Em trabalho anterior (HADDAD, 20I3), discorri sobre as pesquisas de alguns grupos que vêm se dedicando ao tema do profissionalismo em educação infantil no plano internacional, a partir de diversas perspectivas. Procurei identificar seus principais focos de interesse, metodologias empregadas, conceituaçôes, proposiçóes e respectivas publicaçôes. Naquela altura, a literatura brasileira mostrava escassez de estudos sobre profissionalismo em educação infantil que tomasse como ponto de partida a área em questão. Os pressupostos teóricos e epistemológicos que permeavam o debate sobre a docência de forma geral eram referenciados, quase exclusivamente, na lógica da instituição escolar, centrada, sobretudo, nas exigências e deveres de aprendizagem. Nessa perspectiva, esses grupos internacionais inovavam ao buscar e testar novos caminhos para acessar as compreensóes de profissionalismo por aqueles que o praticam e anunciavam a rica diversidade de indivíduos pensando e atuando profissionalmente em seus respectivos contextos de trabalho, contrastando com a tendência dominante de definir a existência de uma profissão da primeira infância. (MILLER; DALLI; URBAN, 20I2)

Considerando o caráter altamente complexo, imprevisível e diversificado dos sistemas de educação infantil pelo mundo, o que essas pesquisas mostravam é que não é uma coleção de práticas, técnicas e circunscritas, que define a profissão, mas um "[...] constante exercício de criar compreensôes compartilhadas, negociar açôes e manter conexóes - entre crianças e adultos, leigos e profissionais, indivíduos e sociedade." (DAHLBERG; MOSS, 2005; DALLI; CHERRINGTON, 2009, apud MILLER; DALLI; URBAN, 20I2, p. I68)

Compreender e dar visibilidade aos contornos dessa profissão por aqueles que estão diretamente ou indiretamente envolvidos com ela e con- 
tribuir para o seu reconhecimento e valorização continuou sendo um objetivo a ser perseguido por mim. $\mathrm{Na}$ ocasião em que realizei essa revisão de literatura, estava finalizando a pesquisa Representaçóes sociais de estudantes de pedagogia sobre o trabalho do professor de educação infantil (2007-2014), em parceria com outras duas universidades federais: Universidade Federal de Mato Grosso (UFMT) e Universidade Federal da Fronteira Sul (UFFS). Trata-se de um estudo interinstitucional e longitudinal que investigou as representaçôes sociais de estudantes de Pedagogia sobre o trabalho do professor de Educação Infantil, na perspectiva da Teoria das Representaçóes Sociais, tendo os estudantes de Pedagogia como sujeitos da pesquisa na situação de ingressantes e de formandos.

Entre outros instrumentos de pesquisa, os estudantes responderam a questôes de associação livre, um questionário perfil e um questionáriocarta sobre o trabalho do professor de Educação Infantil. Na tentativa de contemplar as temáticas que refletissem as principais tensóes próprias desse campo, o principal instrumento de pesquisa adotado, o questionáriocarta, foi composto de 28 questóes abertas e fechadas, reunindo quatro grandes dimensôes e uma síntese: a) Escolha do curso e do campo profissional: opção do curso, visão do outro sobre essa opção, escolha do campo profissional; b) Imagem do trabalho: relativo à motivação e satisfação e dificuldades; c) Imagem do campo profissional e da profissáo: modelos de creche e de pré-escola e imagem da profissão, de acordo com o tipo de instituição; d) Processos de profissionalização: fontes de informação/aprendizagem, incluindo gênero/maternidade, conteúdos da formação, tarefas e expectativas de desempenho do professor de educação infantil; e) Sintese: conselho a um candidato a ser professor de educaçáo infantil. (CORDEIRO; HADDAD; ANDRADE, 20I6)

Além disso, na perspectiva de apreender as representaçóes sociais de trabalho do/a professor/a de EI, atenção especial foi dada ao formato das questóes, na linha desenvolvida por nossos colegas da Universidade Aix-Marseille, na França. Assim, as questóes de múltipla escolha do questionário apresentavam graus progressivos de complexidade: escolha livre, escolha hierarquizada, técnica de substituição e questionário de caracterização. No caso das questóes abertas, as respostas foram submetidas à análise lexical com auxílio do software Alceste ${ }^{1}$. 
Todos esses recursos mostravam sua utilidade para qualificar o objeto da representação social, no caso, o trabalho do/a professor/a de educação infantil. Um exemplo é a análise de uma das dimensôes relativas à Imagem do campo profissional e da profissão em que se aplicou a análise fatorial de correspondências (AFC) para averiguar se diferentes filiaçóes sociais, econômicas e culturais explicam possíveis oposiçôes na adoção de referências profissionais (HADDAD; CORDEIRO; LO MONACO, 20II). As questôes analisadas tratam das tarefas do/a profissional que se ocupa das crianças nas instituiçóes de educação infantil mediante uma lista de 24 itens em que os sujeitos eram solicitados a marcar todos aqueles que se aplicam como tarefas do/a professor/a em contexto de creche e em contexto de pré-escola. O objetivo era identificar que referências profissionais orientam a indicação de tarefas como sendo ou não pertinentes a cada um dos dois contextos. As tarefas foram agrupadas em conjuntos de atividades, tais como as que envolvem: cuidados físicos segurança, higiene e saúde da criança (alimentar, trocar fraldas, banhar, dar remédio e fazer curativos, zelar pela integridade física das crianças); relaçóes interpessoais (dar carinho, atender a crianças com necessidades especiais, transmitir valores); ludicidade (organizar brincadeiras, brincar e passear com as crianças); ensino (ensinar conteúdos escolares, ensinar a ler e a escrever, elaborar e corrigir tarefas didáticas, organizar atividades de recuperação e reforço); o cuidado com o espaço (limpar a sala, preparar o ambiente físico); planejamento e avaliação (observar e avaliar as crianças, escrever relatórios, participar de reunióes pedagógicas, elaborar os planos de atividades, fazer pesquisas); a relação com a família (manter contato com as famílias, organizar reunióes de pais).

A análise prototípica, com base na frequência com que cada item foi escolhido pelo conjunto de respondentes, indicou a existência de referências profissionais distintas associadas às tarefas do professor nos contextos de creche e de pré-escola que se dão, sobretudo, nos polos das tensóes que têm caracterizado o debate sobre profissionalização na educação infantil: cuidar versus ensinar conteúdos escolares; brincadeira versus tarefas didáticas; relaçóes baseadas na afetividade versus relaçóes pautadas nas normas sociais e morais. No entanto, na utilização da AFC observou-se uma polifasia cognitiva na representaçáo das tarefas do professor quanto se trata do contexto da creche, expressa em diferentes tomadas de posição relacio- 
nadas com as filiaçóes socioeconômicas e sociais dos sujeitos, enquanto o modelo escolar, que determina o modo de pensar a pré-escola, não é afetado por elas. Essa evidência sugeria a existência de uma representação hegemônica de escola contribuindo para

perpetuar a dominância do modelo escolar como referência profissional em todos os contextos educacionais, o que, no caso da educação infantil, dificulta a construção de um novo perfil, mais adequado às tarefas dos profissionais responsáveis pelo cuidado e pela educação das crianças pequenas. (HADDAD; CORDEIRO; LO MONACO, 20II, p. I52)

Apesar de os resultados confirmarem nossas hipóteses iniciais, algo me incomodava no conjunto dessa pesquisa e se fazia objeto de reflexáo quando comparada à pesquisa de minha colega dinamarquesa Jytte Juul Jensen (20II; 20I6), um dos estudos analisados em trabalho anterior (HADDAD, 20I3) e que será objeto deste artigo. Jensen realizou uma pesquisa sobre compreensóes de práticas pedagógicas em educação infantil que envolveu a filmagem do cotidiano em três países europeus: Dinamarca, Inglaterra e Hungria, por meio de um método visual inovador que combina apresentação de filmes em grupos focais formados por diferentes perfis de 'observadores'. Trata-se do Sophos, acrônimo para Second Order Phenomenological Observation Scheme, indicando o foco nas observaçóes de segunda ordem. Ao se utilizar do Sophos, o pesquisador estará observando pessoas que estão observando a prática pedagógica apresentada em filme. Conforme argumenta Cameron (2007), a adoção de filme como recurso metodológico em pesquisa priorizava, até recentemente, o uso da imagem visual como fonte de dados, como observação 'de primeira ordem', caracterizado pelo registro de comportamento de sujeitos (crianças ou adultos), para posterior análise pelos pesquisadores. Em Sophos, ao contrário, os dados são gerados por meio das observaçôes feitas sobre a imagem visual por grupos selecionados, tornando-se uma observação de 'segunda ordem'.

Voltando para as minhas inquietaçóes com a pesquisa anterior, embora as duas pesquisas compartilhassem objetos semelhantes, representaçôes sociais do trabalho do professor/a de educaçáo infantil e compreensóes 
da prática pedagógica nessa etapa da educação, os meios para realizá-las divergiam severamente. Enquanto o nosso questionário tinha 28 questôes, a pesquisa de Jensen apresentava uma única questão aos sujeitos participantes da pesquisa (o que veio à mente ao assistir aos filmes?). Enquanto os procedimentos de coleta e análise dos dados do questionário eram muitos sofisticados, os resultados não eram tão ricos e surpreendentes em conteúdo quanto as narrativas geradas nas discussóes sobre os filmes em grupos focais da pesquisa dinamarquesa. Além disso, em nossa pesquisa a participação dos sujeitos na indicação dos temas e na polarização das tensôes era mínima. Se a educação infantil é um campo de conhecimento que guarda especificidades em relação a outras etapas da educação básica, o nosso questionário náo permitia que essas especificidades fossem trocadas em miúdo pelos participantes da pesquisa.

Todas essas inquietaçóes me levaram ao desejo de realizar uma réplica da pesquisa de Jensen, o que ocorreu a partir de dezembro de $2014 \mathrm{com}$ a aprovação do projeto de pesquisa submetido ao CNPq. Jensen aceitou participar como colaboradora e consultora da pesquisa, facilitando a edição de outro filme em uma instituição de educação infantil na Dinamarca e orientando-nos quanto à utilização do Sophos. A edição brasileira da pesquisa produziu dois filmes de situaçóes do cotidiano de duas instituiçóes de educação infantil, um em Maceió, Alagoas, Brasil, e outro em Aarhus, Dinamarca, utilizados para obter compreensóes da prática pedagógica em educação infantil. Ao realizar essa pesquisa aprofundei meu conhecimento sobre duas abordagens metodológicas de pesquisa qualitativa que utilizam filmes para obter compreensóes sobre a prática pedagógica em educação infantil: a etnografia visual e multivocal desenvolvida por Tobin e colaboradores, que deu origem à clássica obra Educação infantil em três culturas: Japão, China e Estados Unidos (TOBIN; WU; DAVIDSON, 2008) e ao Sophos, grandemente inspirado pela primeira pesquisa.

Com o intuito de contribuir para enriquecer o debate sobre metodologias que valorizam a voz dos que fazem a educação infantil (professores, pais, crianças, acadêmicos, estudantes, gestores, dentre outros agentes) este artigo foca na apresentação dessas duas abordagens, discutindo semelhanças e diferenças, por meio da descrição das respectivas pesquisas. 


\section{A etnografia multivocal e visual de Joseph Tobin e colaboradores}

A clássica pesquisa de Tobin, Wu e Davidon (2008), que deu origem à obra Educação infantil em três culturas: Japão, China e Estados Unidos, compara práticas de educação infantil nesses três países com o uso de filmes, para estimular um texto multivocal. A pesquisa, realizada em meados da década de 1980, reflete um movimento de resistência à tendência dominante da pesquisa qualitativa que se voltava ao teste de crianças para medir a eficácia de abordagens pedagógicas e a frequência da interação criança-professor, para computar os dólares gastos por criança na escola ou tabular o tempo que as crianças gastam em exercícios de aprendizagem da leitura (TOBIN; WU; DAVIDSON, 2008, p. I2-I3) Marcando posição distante da ideia de classificar as instituições de educação infantil nas três culturas estudadas em boas ou más, os autores deslocam o foco da investigação para a evocaçấo de significados e compreensôes sobre o que elas se dispóem a fazer e ser.

Dessa forma, ousam na elaboração de um método que se tornaria referência entre acadêmicos de todo o mundo preocupados com o domínio de uma interpretaçáo restrita da psicologia do desenvolvimento e da teoria do desenvolvimento infantil, e que adotavam perspectivas mais críticas, feministas, pós-coloniais, pós-modernas e indígenas em seu trabalho $^{2}$. Tal método deveria permitir reverter os desequilíbrios de poder encontrados em grande parte das pesquisas educacionais comparativas, nas quais "os ocidentais estudam não-ocidentais, brancos estudam nãobrancos, estudiosos estudam praticantes e homens estudam mulheres e crianças." (TOBIN; DAVIDSON, I990, p. 27I) Assim, a proposta é uma etnografia multivocal ou polivocal como estratégia de empoderamento de professores e outros atores para falar diretamente nos textos dos autores. No coração do método está o uso de filmes para estimular o discurso polivocal.

O estudo em questão implicou a produção de três filmes que buscam evidenciar um dia mais ou menos típico em uma instituição de educação infantil dos três países escolhidos. A primeira voz introduzida na pesquisa de Tobin e colaboradores é a etnografia visual, ou seja, a filmagem de um dia mais ou menos típico de uma instituição de educação infantil desses 
países. Essas etnografias visuais mostram cenas de chegada e partida, brincadeiras dentro e fora da escola, atividades de grupo estruturadas, almoço, banheiro e horário de sono, mescladas com cenas de interação entre pais e filhos, crianças e professores, crianças e crianças, além de episódios de brigas e cooperaçáo entre crianças e professores ensinando, consolando e disciplinando. A escolha das instituiçóes seguiu alguns critérios: haveria de ser boas instituiçôes (e não 'medíocres'); de classe média (em oposição às de elite); de áreas urbanas da China, Japão e Estados Unidos; cujos gestores, professores e pais se sentissem relativamente à vontade para serem filmados e fotografados e livres para entrarem em diálogo com a equipe de pesquisa. A escolha das salas ou turmas de crianças também seguiu uma lógica semelhante. Em cada instituição foi solicitada permissão para primeiramente filmar uma sala de crianças de quatro anos de idade. Quando mais de uma sala estava disponível era solicitado ao diretor que selecionasse uma sala cujo/a professor/a não se sentisse desconfortável em ser filmado/a e estivesse disposto/a a se encontrar com a equipe algumas vezes durante o ano seguinte da filmagem para "discutir suas estratégias de ensino." (TOBIN; WU; DAVIDSON, 2008, p. I4-I5) Para tornar as vídeo-gravaçóes mais acessíveis e interessantes aos espectadores a opção da equipe foi focar duas ou três crianças em cada sala.

$\mathrm{O}$ resultado desse empreendimento foi a edição de três filmes de 20 minutos cada sobre o cotidiano da educação infantil nos três países envolvidos, considerados pela equipe como "muito subjetivos, idiossincráticos, condicionados culturalmente" (op. cit, p. I6) e, ainda, consistente com o método utilizado. Uma vez que os filmes são utilizados não como dados, mas como a primeira voz em um diálogo, a edição cuidou de recortar episódios que tinham o potencial de estimular discussão e salientar desacordos sobre, por exemplo, a "missão da pré-escola" e "a natureza da criança". (TOBIN; DAVIDSON, I990, p. 27I)

O próximo passo foi retornar ao campo e mostrar os filmes editados para os profissionais e as crianças de cada instituição filmada. Conforme assistiam aos filmes, eram indagados a explicar o que viam. As reaçóes dos professores, administradores e crianças às etnografias visuais filmadas nas respectivas salas/turmas de crianças, ou seja, as explicaçôes das pessoas envolvidas (insiders), são consideradas a segunda voz do estudo. 
O terceiro passo foi mostrar as filmagens aos pais, funcionários e especialistas em educação infantil em cinco ou mais instituições de cada país, com vistas a explorar o grau de tipicidade das instituiçóes escolhidas. As reaçóes dessas audiências constituem a terceira voz do estudo, a voz dos 'de fora' (outsiders), uma narrativa de peso que oferece uma contextualizaçáo tanto para os filmes quanto para as explicaçóes dos envolvidos (insiders). Foram registradas reaçóes de aproximadamente 750 informantes, dentre pais, professores, gestores, especialistas em desenvolvimento infantil e estudantes universitários de cada país (300 japoneses, 240 chineses e 2 IO norte-americanos). Além de assistirem aos filmes, esses outsiders foram solicitados a preencher um questionário com questões tais como: "Quais são as três razóes mais importantes para uma sociedade ter pré-escolas? ", "Quais são as coisas mais importantes que as crianças devem aprender na pré-escola? ” e "Quais são as características mais importantes de um bom professor de pré-escola?” (TOBIN; WU; DAVIDSON, 2008, p. I93) Esses questionários com questóes de classificação foram utilizados não para testar hipóteses ou demonstrar correlaçôes estatísticas, mas para facilitar a comparação intercultural de como as três culturas priorizam a função da pré-escola. O último passo da pesquisa de campo foi mostrar os filmes para uma audiência internacional, no caso, os profissionais das instituições filmadas nos países envolvidos na pesquisa. Assim, as reaçôes de professores, gestores e pais chineses, japoneses e estadunidenses aos filmes que assistiam constituíram a quarta voz do estudo. Nessa fase da pesquisa, ao serem solicitados a analisar as duas outras instituiçóes filmadas, os informantes também desempenharam o papel de etnógrafos, de acordo com Tobin e Davidson (1990, p. 272):

Esses "julgamentos externos" (LeVine, 1966) inevitavelmente refletem uma mistura da cultura descrita e da cultura que faz a descrição. Assim, por exemplo, as declaraçôes de um professor japonês sobre uma pré-escola americana têm algo a nos ensinar sobre as crenças e valores japoneses e americanos.

Com o ajuizamento de terceiros, os autores da pesquisa pretendiam tornar o projeto mais verdadeiramente intercultural e menos transcultu- 
ral, argumentando que a obra não versa apenas sobre três culturas, mas contempla a perspectiva das três culturas, à medida que contém "interpretaçóes japonesas, chinesas e norte-americanas sobre eles mesmos e sobre o outro." (TOBIN; WU; DAVIDSON, 2008, p. I8) Mais uma vez esses julgamentos e análises foram registrados tanto por meio da gravação das discussóes quanto pelo preenchimento do mesmo questionário utilizado na fase anterior.

Por fim, o estudo contempla ainda uma quinta voz que se refere a todas essas etapas reunidas em um manuscrito, produzindo uma 'dialética multivocal' de interpretação, avaliação e crítica, à medida que "cada uma dessas vozes, cada camada textual, reage aos textos anteriores sem substituí-los, subsumi-los ou negá-los inteiramente." (TOBIN; DAVIDSON, I990, p. 272) Conforme afirmam os autores:

Esta abordagem de pesquisa foi concebida para capacitar os informantes, substituindo a autoridade etnográfica tradicional por polivocalidade, e para descentralizar o texto de seus autores, deslocando o poder da reflexividade do metadiscurso do etnógrafo para a compreensão de crianças, professores e administradores de educação infantil. (id.ib.)

Tobin e colaboradores argumentam que o filme em geral é uma narrativa etnográfica que congela as pessoas e as instituiçóes no tempo e as isola de seus contextos. Para neutralizar essa tendência, acrescentaram ao manuscrito valiosas informaçóes sobre o contexto de cada instituição filmada nos três países, abarcando, por exemplo: a política familiar do filho único que havia sido introduzida na China; a tensão histórica e contemporânea entre as creches de classes trabalhadoras e as escolas maternais de classe média no Japão; e a tensão trabalho da mulher, responsabilidades familiares e expectativas dos papéis de gênero presentes nas narrativas de pais e professores dos Estados Unidos. À missão explícita de documentar a diversidade de crenças humanas e instituiçóes, o estudo de culturas estrangeiras, conforme os autores enquadram a pesquisa, também funciona como "uma forma de crítica cultural para nós mesmos." (MARCOS; FISHER, 1986, apud TOBIN, WU; DAVIDSON, 2008, p. I9) Assim, 
anunciam os dois objetivos perseguidos no estudo: transformar o exótico em familiar e tornar o familiar exótico.

Tobin atribui uma abordagem Rashomoniana à primeira voz, ou seja, às narrativas videogravadas de 'dias típicos' em centros de educação infantil, que constituem o ponto de partida para as discussóes. Refere-se ao clássico filme de Akira Kurosawa, Rashomon (I950), que mostra diferentes versóes e conclusôes do mesmo crime, um "contar e recontar dos mesmos eventos videogravados de diferentes perspectivas, um diálogo contínuo entre os de dentro e os de fora, entre praticantes e pesquisadores, e entre pessoas das três culturas diferentes." (TOBIN, I989, p. 176, apud TOBIN; DAVIDSON, I990, p. 27I)

Outra fonte de influência são os filmes etnográficos $A$ Balinese Trance Séance (1980) e Jero on Jero: A Balinese Trance Séance Observed (198I). Uma equipe composta pelos cineastas Timothy e Patsy Asch e a antropóloga Linda Connor havia colaborado na produção do primeiro filme que versa sobre Jero Tapakan, massagista balinesa que atua como médium, encontrando clientes em sua casa e entrando em transe para permitir que deidades e outros espíritos falem a eles por meio dela. $\mathrm{O}$ segundo filme documenta a volta da equipe a Bali para mostrar a Jero as filmagens dela em transe e pedir que comente suas açóes (BANKS, 2009). O filme resultante apresenta algumas das reaçóes de Jero a Connor enquanto ela assistia e ouvia a si mesma pela primeira vez. Seus comentários fornecem insights sobre como ela se sente enquanto possuída, sua compreensão da feitiçaria e sua humildade na presença do mundo sobrenatural. A contribuição metodológica específica de Tobin e equipe pode ser resumida na citação abaixo:

[...] combinar esse uso do vídeo como uma ferramenta de feedback (Rouch, 1995) e como um "dispositivo mnemônico" (Asch \& Asch, 1995), com o apelo de James Clifford de 1983 para que as etnografias fossem textos multivocais, a advertência de Jay Ruby de que os filmes etnográficos não devessem ser considerados dados objetivos, mas espelhos reflexivos (1982), e os escritos de Mikhail Bakhtin sobre heteroglossia, dialogismo e responsabilidade (I98I, I986, I990). O resultado é um método no qual a videogravação é usada para provocar a 
reflexão não apenas dos professores filmados, mas também de seus colegas, seus supervisores e suas contrapartes em outras cidades e outros países. (TOBIN; HSUEH, 2007, p. 78)

Além das fontes contidas na citação acima, Tobin e colaboradores também se inspiram na antropologia visual de Margaret Mead (1972/1995) e na metodologia descolonizante de Linda Smith (I999), em especial no importante papel que ambas atribuem ao público estudado e filmado para a pesquisa e nos insights sobre como a etnografia pode ser reestruturada de modo a servir aos interesses daqueles que tradicionalmente têm sido objetos, mas náo sujeitos ou público da antropologia.

\subsection{A educação em três culturas revisitada}

Vinte anos depois, acrescentando uma dimensão histórica ao primeiro projeto, cujo início data de 1984, Tobin volta a campo com outra equipe de pesquisadores para iniciar o segundo projeto, Preschool in Three Cultures Revisited: China, Japan, and the United States, publicado em 2009 por Tobin, Hsueh e Karasawa. Estimulados pelas dramáticas mudanças no campo da educaçáo infantil, especialmente na China, o foco agora volta-se para o que permanece e o que muda ao longo de vinte anos, isto é, como o sistema de educação infantil nesses três países "refletem e transmitem os valores culturais, respondendo simultaneamente às mudanças nas pressôes e expectativas sociais sobre o que as crianças pequenas devem aprender, fazer e ser." (TOBIN; HSUEH; KARASAWA, 2009 , p. I) Na mesma linha do primeiro estudo, esse processo de continuidade e mudança é narrado pelas vozes (explicaçóes e reflexóes) dos que fazem a educação infantil, com a utilização do mesmo método que passa a ser nomeado de 'etnografia multivocal sugerida por vídeo' (videocued multivocal ethnography). Essa designação ilustra mais claramente a função primária dos filmes: "uma rica sugestão não-verbal projetada para estimular a reflexão crítica" (TOBIN; HSUEH, 2007, p. 77-78), e não dados ou descriçóes.

$\mathrm{Na}$ prática, o método seguiu o mesmo desenho do estudo anterior: (I) filmagem de um dia em uma instituição pré-escolar; (2) edição de até 
20 minutos do material videogravado; (3) exibição do filme editado para o/a professor/a da sala, e solicitação de comentários e explicaçôes da prática registrada; (4) discussóes em grupo focal do filme com outros profissionais da instituição; (5) discussôes em grupos focais com profissionais de outras instituiçóes pré-escolares em todo o país (para abordar a questão da tipicidade); e (6) discussóes em grupo focal com o pessoal das instituiçóes de educação infantil nos dois outros países do estudo. A maior mudança metodológica em relação ao primeiro estudo foi a decisão pela filmagem de duas instituiçóes em cada país ao invés de uma, como forma de colocar a questão da mudança e permanência em primeiro plano.

\section{O método Sophos de Hansen e Jensen (2004)}

Conforme mencionado anteriormente, o método Sophos foi desenvolvido e testado por duas pesquisadoras dinamarquesas, Jytte Juul Jensen e Helle Krogh Hansen (HANSEN; JENSEN, 2004) no contexto do projeto Care Work in Europe: Current Understandings and Future Directions desenvolvido no período de $200 \mathrm{I}$ a 2005 e coordenado por Claire Cameron e Peter Moss (CAMERON; MOSS, 2007). Financiado pela Uniáo Europeia, o projeto envolveu pesquisadores de seis países da Europa: Dinamarca, Espanha, Hungria, Holanda, Suécia e Reino Unido e tinha o amplo objetivo de contribuir para o desenvolvimento de emprego de qualidade para trabalhadores do cuidado e do trabalho pedagógico, com vistas a satisfazer as exigências dos cidadãos em uma sociedade em rápida mudança.

Três etapas compuseram o projeto: a) mapeamento e revisão de literatura da força de trabalho, incluindo uso e demanda de serviços voltados ao cuidado sobre a qualidade, satisfação no trabalho e questôes de gênero; b) três estudos de caso transnacionais, com crianças pequenas que frequentam instituiçóes de educação infantil (na Dinamarca, Hungria e Espanha), idosos e adultos com deficiências graves (Dinamarca, Hungria), além da introdução de métodos de videogravação para estudos transnacionais de prática de cuidado; e c) monitoramento e análise de práticas inovadoras de trabalho de cuidado entre os países parceiros da pesquisa ${ }^{3}$. 
Sophos resulta de parte da segunda etapa, ou seja, do empenho em desenvolver um método para o estudo transnacional de práticas de cuidado de idosos e trabalho pedagógico com crianças, envolvendo três países: Dinamarca, Inglaterra e Hungria, que respondesse a seguinte pergunta: "Como ir além das palavras e conceitos que são usados em diferentes culturas e contextos de forma que parecem similares na superfície, mas que, de fato, cobrem diferentes visôes e valores subjacentes?” (JENSEN, 2004, p. 5) A proposta foi a utilizaçáo de videogravação nos mesmos moldes da abordagem utilizada por Tobin, Wu e Davidson (1989) para a pesquisa transcultural que investigou a educação infantil em três culturas.

Assim, seis filmes foram produzidos, dois em cada país, sendo um sobre a prática pedagógica de um dia em uma instituição de educação infantil e outro sobre o cuidado com idosos. Esses seis filmes editados foram exibidos nos três países para vários grupos de pessoas envolvidas direta ou indiretamente com a prática desses dois tipos de contextos.

Embora o trabalho de Tobin, Wu e Davidson (1989; 2008) figure como a principal fonte de inspiraçáo, a abordagem de Hansen e Jensen difere de forma tão significativa que as levou ao desenvolvimento de uma metodologia que foi denominada Sophos, um acrônimo para Second Order Phenomenological Observation Scheme, conforme já mencionado.

O objetivo maior do Sophos é obter insight de como uma determinada prática é vista pelos que a praticam e por outros grupos que de uma forma ou de outra estáo intimamente associados a essa prática. O modelo é, portanto, designado como fenomenológico. (JENSEN, 2004, p. 4-destaque da autora)

Hansen e Jensen (2004) argumentam que Tobin e seus colegas se propuseram a comparar instituições de educação infantil nesses três países. Eles queriam descobrir a que fim essas instituiçôes se destinavam e esperavam videogravar situaçôes comparáveis, enfatizando que comparar diferentes culturas é muito difícil. Eles se comunicaram com os participantes durante todo o processo e se reuniram, em diversas ocasióes, com os professores das instituiçóes filmadas para discutir suas estratégias de ensino. Também empregaram outros métodos de investigação, como 
questionários, e investiram em explicar as origens sociais e culturais das práticas nesses três países. Seu trabalho meticuloso levou muito tempo e, além de estudar as instituiçôes de educação infantil, eles também estudaram as "três culturas vistas por meio de suas instituiçôes pré-escolares", argumentando que pré-escolas são "instituiçôes complexas que atendem crianças, pais, e, indiretamente, toda a sociedade." (HANSEN; JENSEN, 2004, p. 6-7)

Outro aspecto ressaltado pelas autoras é que a pesquisa realizada pela equipe de Tobin foi originalmente inspirada em uma abordagem etnográfica na qual o material filmado é utilizado para estimular um "segundo nível de discurso reflexivo." (TOBIN; WU; DAVIDSON, I989, p. I3) No entanto, as autoras argumentam que os pesquisadores não aplicaram a técnica de filmografia exatamente da maneira como reza a sua fonte de inspiração, e sim para gerar um texto multivocal. Ao envolver as 'vozes' de vários observadores, Tobin e equipe foram capazes de estudar diferentes culturas de uma maneira muito peculiar, olhando para cada cultura préescolar a partir de uma série de perspectivas.

Assim, Sophos difere do trabalho de Tobin e colaboradores em duas maneiras principais: primeiro, não há nenhuma tentativa de entender as crenças e valores expressos por observadores como reflexo da cultura de seu país; segundo, enquanto estudo fenomenológico, os pesquisadores têm um papel interpretativo que vai muito além de retransmitir os significados atribuídos pelos participantes. Tal interpretação insere a pesquisa também numa perspectiva hermenêutica crítica. (CAMERON, 2007)

$\mathrm{Na}$ linha da pesquisa de Tobin e colaboradores, a pesquisa de Hansen e Jensen (2004) solicitou a grupos de pessoas dos três países (Dinamarca, Inglaterra e Hungria) a tecerem comentários sobre a prática de cuidados e de trabalho pedagógico nas seis instituiçóes filmadas (de idosos e crianças), mas não fizeram o trabalho de etnógrafos que estão estudando culturas estrangeiras. Uma equipe de pesquisadores de cada país se envolveu no estudo de como pedagogos e outros trabalhadores, especialistas, formadores, crianças e pais discutiram exemplos da prática mostrada nos filmes do seu país e dos outros dois países. Em seguida, as respostas dos observadores participantes nos grupos focais de cada país foram analisadas em uma perspectiva nacional cruzada. As autoras do método se dividiram para a realização dos estudos, sendo que Hansen se 
responsabilizou pela pesquisa com idosos e Jensen com a prática pedagógica em educação infantil.

Uma vez explicitada a diferença entre as duas abordagens, daremos destaque à pesquisa realizada por Jensen voltada à compreensão da prática pedagógica em educação infantil.

\section{I O desenho da pesquisa}

Diferentemente da pesquisa de Tobin e colaboradores, em que a equipe se deslocou pelos três países, na pesquisa Care Work in Europe foi decidido que os pesquisadores de cada país - Dinamarca, Inglaterra e Hungria - iriam apresentar o filme, analisar e interpretar as respostas e, em seguida, preparar relatórios nacionais. Assim, a pesquisa em cada país foi realizada por pesquisadores que se identificavam, linguística e culturalmente, com os grupos de observadores, reconhecendo os sinais, mas também partilhando suposiçóes. Um filme de 30 minutos foi produzido em cada país, em um centro de educação infantil escolhido pelos pesquisadores nacionais, com base em situaçôes específicas do cotidiano educacional e focado em dois professores.

O filme dinamarquês foi filmado em um centro de idades integradas com crianças de o a 5 anos administrado pelo município, acompanhando um pedagogo com um grupo de crianças de o a 3 anos e um pedagogo com um grupo de crianças de 3 a 5 anos. $\mathrm{O}$ filme inglês exibe a prática de uma escola materna privada, com crianças de 2 a 3 anos, acompanhando dois educadores que trabalham juntos a maior parte do dia. $\mathrm{O}$ filme húngaro apresenta práticas de uma creche com crianças menores de 3 anos de idade e acompanha dois educadores e grupos de crianças com os quais trabalham. $\mathrm{O}$ mesmo cinegrafista (dinamarquês) realizou todas as filmagens e trabalhou com os pesquisadores nacionais para as respectivas ediçôes de forma a garantir um produto qualitativamente uniforme. As narrativas foram traduzidas para as outras duas línguas parceiras e as traduções foram legendadas nos filmes.

Os filmes dos três países foram entáo mostrados para vários grupos de observadores em cada país, em grupos focais de 2 a 5 pessoas, além dos pesquisadores. $\mathrm{O}$ perfil desses grupos variou entre os três países, mas 
em geral envolveu os próprios atores sociais (crianças e professores que as acompanhavam), professores de criança, especialistas, formadores, estudantes e pais. Algumas informaçóes básicas sobre os observadores foram obtidas por meio de conversas e questionários que cobrem detalhes pessoais e pontos de vista sobre a prática.

\subsection{Questóes éticas}

O método coloca uma série de questôes éticas, como cenas que envolvem situaçôes de muita intimidade, incluindo cuidados físicos, expondo e tornando visível a prática de alguns profissionais a uma ampla gama de observadores. Evitar expor pessoas em uma situação na qual se sentem exploradas, expostas ou humilhadas foi uma questáo considerada. Embora fosse um requisito que dois profissionais (professores ou pedagogos) estivessem no ponto focal de cada filme, muitas cenas acabam envolvendo outros profissionais. Da mesma forma ocorreu com as crianças de outros grupos que apareciam nos filmes. Em todos os casos, as pessoas filmadas foram convidadas a assinar o seu consentimento como atores do filme. No caso das crianças essa permissão era solicitada aos pais. Certas regras foram aplicadas sobre o que não poderia ser filmado, embora tenha sido decidido não excluir todos os exemplos de cuidados íntimos, pois isso daria uma falsa imagem da prática. Os atores sociais tiveram a oportunidade de se retirar do projeto durante o seu curso ou depois de ter visto o filme. Para isso, os filmes foram mostrados a eles após a primeira edição antes de serem exibidos para qualquer outro grupo. Entretanto, não ocorreu nenhuma circunstância de algum participante retirar ou solicitar a exclusão de alguma cena específica.

Os problemas éticos não apenas se relacionam com a produção de filmes. A equipe de pesquisa também enfrentou problemas específicos com uma série de observadores comentando sobre a prática que havia sido filmada. As autoras argumentam que foram capazes de garantir o anonimato dos observadores que deram seus comentários, mas não de evitar os pontos de vista sobre os filmes editados, o que cria um risco de atores sociais experimentarem sua própria prática (filmada) sendo discutida e criticada. (HENSEN; JENSEN, 2004) 


\subsection{O processo de exibição e discussáo de filmes pela equipe da Dinamarca}

As reuniōes com cada grupo foram iniciadas com uma breve repetição das informações fornecidas aos participantes com antecedência. A pesquisadora organizou as apresentaçóes para todos os grupos de observadores, ressaltou que os três filmes não apresentam a vida real, mas sim uma interpretaçáo da prática, editada e retirada de um contexto maior; sublinhou que os observadores eram livres para comentar e discutir qualquer coisa que pudesse surgir. Além disso, houve uma explicação da razão pela qual as sessóes seriam registradas em vídeo e áudio, bem como a forma como o material seria tratado. $\mathrm{O}$ projeto original de pesquisa previa três sessóes de apresentação para cada grupo de observadores, uma para cada filme, estimada em duas horas cada. O filme deveria ser apresentado duas vezes, primeiro sem interrupção e novamente depois de um breve intervalo, com pausas quando um dos observadores tivesse algo a dizer ou o grupo iniciasse uma discussão espontânea.

$\mathrm{Na}$ Dinamarca isso ocorreu de outra maneira. A primeira exibição do filme dinamarquês, que ocorreu durante uma manhá, foi para os dois atores sociais, as duas pedagogas que figuram no filme, pois além de usar seus comentários como material de pesquisa, havia a necessidade de consulta-las se concordavam com o filme, especificamente as cenas em que figuravam, e se certas cenas exigiam a aprovação dos pais. Caso isso acontecesse, pesquisadora e cinegrafista fariam essas alterações. Ambos os atores ficaram satisfeitos com o filme, que, portanto, foi mantido sem alteraçôes.

Dois meses depois, quando os outros dois filmes estavam com as legendas colocadas, o filme inglês e em seguida o filme húngaro foram exibidos aos dois atores sociais. As pedagogas viram os dois filmes em um dia (não como originalmente planejado), seguindo a proposta de assistir primeiro sem pausa e depois pausando quando tinham comentários. Como já fazia muito tempo desde que elas tinham visto o filme dinamarquês, fizeram poucas referências a esse filme.

A próxima apresentaçáo foi para o grupo de especialistas que viram os três filmes em um dia, num intervalo de tempo de cinco horas. A ideia de mostrar todos os filmes em um dia justificava-se pelo fato 
de que a comparação entre os três filmes era mais óbvia, uma vez que tinham os três filmes em suas mentes, o que se confirmou com o grande envolvimento dos observadores durante a maior parte da apresentação. Para esse grupo, o filme dinamarquês foi exibido primeiro, seguido pelo inglês e, finalmente, pelo filme húngaro. Todos os especialistas tinham muito a dizer sobre todos os filmes e, ao final das três apresentaçóes, foram discutidas diferenças e semelhanças entre as práticas mostradas nos três filmes. Ao notar que a exibição do filme dinamarquês suscitava pouca comparação com as práticas nos outros países, a pesquisadora decidiu inverter a ordem e deixar o filme dinamarquês por último. A ideia por trás dessa decisão é que o confronto com a prática de outro país (não familiar) forneça ao observador uma imagem muito mais clara da teoria, prática e valores culturais de seu próprio país. De fato, foi mais produtivo mostrar os filmes nessa sequência. Após as discussóes sobre a prática de dois outros países, os observadores estavam mais conscientes do que era especificamente dinamarquês, o que foi discutido em resposta ao filme dinamarquês. Jensen (2004) argumenta que a decisão sobre a ordem de exibição ocorra em função da pergunta da pesquisa e dos interesses do pesquisador, e orienta que o pesquisador experimente a ordem dos filmes exibidos. No caso dessa pesquisa, seu interesse era transnacional: obter compreensóes de observadores dinamarqueses de semelhanças e diferenças na prática em três países.

Uma vez definida a ordem de apresentação dos filmes e a não necessidade da segunda exibição dos filmes, pois contribuía para quebrar a intensidade da discussáo em grupo, o restante das exibiçóes para os grupos de especialistas, formadores, estudantes e pais seguiu o mesmo formato. Uma observação a ressaltar é o quanto a pesquisadora se surpreendeu com a capacidade dos observadores de lembrarem das cenas dos filmes com detalhes e se engajarem na discussão e reflexão por um longo período sem aparentar cansaço.

Outra questão importante em relação ao processo de exibição e discussão dos filmes é a organização do ambiente físico. A pesquisadora cuidou para que todos os observadores fossem posicionados adequadamente em relaçáo à TV, dispôs a filmadora a distância para que todos pudessem ser vistos na tela e utilizou um gravador para que todos os comentários dos participantes pudessem ser ouvidos. As discussóes gravadas em áudio fo- 
ram transcritas e as gravações em vídeo são usadas como suplemento para identificar quem está dizendo o que, além de ser um recurso para estudar a linguagem corporal, se for o caso.

Nessa abordagem, o papel do pesquisador durante as apresentações é observar e apoiar sem controlar os comentários e discussões. Jensen (2004) relata que sua intenção foi fazer perguntas apenas para motivar a discussão entre os participantes, fazê-los desenvolver suas visóes e aumentar sua própria compreensão do que eles diziam. Algumas perguntas foram mantidas até o final, por exemplo, sobre semelhanças e diferenças nos três filmes. Assim como a questão sobre a ordem das apresentaçôes, o papel do pesquisador depende do foco da pesquisa.

\subsection{As exibiçóes para os pais}

O objetivo da exibição foi gerar discussão no grupo de pais e obter suas perspectivas sobre o estudo. Devido ao foco transnacional da pesquisa, todos os três filmes foram incluídos na exibição. Originalmente, os pais não faziam parte do projeto e, portanto, o tempo de apresentação foi reduzido devido a recursos limitados. Eles viram apenas io minutos de cenas selecionadas de cada um dos três filmes, que formaram a base da discussão. A instituição foi responsável pela seleção de quatro pais com base nas crianças que participaram do filme. A sessão foi realizada na sala de professores da instituição em uma tarde antes do horário de encerramento e durou 90 minutos. A exibição dos recortes funcionou bem. Os observadores pais fizeram vários comentários sobre os três filmes. Como esperado, estavam claramente preocupados com seus próprios filhos quando vistos no filme dinamarquês. Depois desse filme dois observadores disseram que gostariam de assistir aos três filmes no total. Eles deixaram claro durante e após a exibição que a sessão foi emocionante e instrutiva. Assim, o método aplicado demonstrou seu profícuo uso na obtenção da perspectiva dos pais sobre a prática pedagógica e evidenciou que mesmo os recortes podem ser usados como um trampolim para discussóes sobre esse objeto de pesquisa. 


\subsection{As exibiçóes para as crianças}

Organizar uma sessão de exibição de filmes para as crianças teve como objetivo provocar discussão nesse grupo de observadores e obter sua compreensão da prática pedagógica, contribuindo assim para introduzir a perspectiva delas a neste estudo. Seu papel não era diferente do dos outros grupos de observadores. Conforme salienta a pesquisadora, referindo-se a Langsted (I994), subjacente à percepção delas está a imagem da criança como especialista da vida no centro de educação infantil que frequenta, que as crianças são respondentes igualmente confiáveis como os adultos e que a inclusão de suas discussóes e compreensóes é importante porque elas são as verdadeiras usuárias dos centros.

Para esse grupo foram exibidas apenas cenas selecionadas do filme dinamarquês, uma vez que os dois filmes estrangeiros eram legendados, o que permitiu examinar os aspectos que elas destacaram quando assistiram. A instituição fez a seleção das quatro crianças que frequentavam o grupo do jardim de infância apresentado no filme. Duas delas tinham quatro e cinco anos e duas outras, seis, sendo dois meninos e duas meninas. Antes da exibição, seus pais haviam fornecido consentimento por escrito para sua participação.

As quatro crianças mostraram-se claramente interessadas em participar da exibição. Antes da apresentação, a pesquisadora contou sobre o filme e o papel delas na pesquisa, que suas opinióes e explicaçóes dos eventos mostrados no filme eram necessárias, uma vez que conheciam a instituição. Elas fizeram vários comentários e tiveram muitas discussóes sobre o filme dinamarquês. Como esperado, estavam claramente preocupadas consigo mesmas, as outras crianças e sua participação no filme. $\mathrm{O}$ tempo de exibição e discussão durou cerca de 40 minutos e elas se mantiveram muito focadas durante toda a sessão, sinalizando que a exibição do filme poderia ter durado mais tempo. A exibição das cenas do filme dinamarquês para os observadores infantis funcionou bem. No entanto, a pesquisadora sugere que embora elas não entendam o que é dito nos filmes estrangeiros, mostrar recortes dos dois outros filmes para observar seus comentários e discussôes pode enriquecer ainda mais a perspectiva desse grupo. 
Após a testagem do método, a pesquisa na Dinamarca seguiu financiada pelo Sindicato dos Pedagogos da Dinamarca (BUPL), com objetivo de analisar as compreensóes dinamarquesas de boa prática pedagógica com o material empírico gerado nas sessóes de exibição dos filmes (JENSEN, 20II, 20I7) e elaborar um caderno eletrônico para apoiar processos de formação de professores de educação infantil. (JENSEN, 2015)

\section{Consideraçóes finais}

Apresentamos duas abordagens metodológicas de pesquisa qualitativa que utilizam filmagens para gerar material empírico de análise. Embora haja diferenças significativas no que tange ao objeto da pesquisa, ambas mostram o potencial da utilização de filmes para suscitar reflexão, expondo os participantes a novas questôes e perspectivas e, dessa forma, desafiando suposiçóes tomadas como certas. (TOBIN et al, I990)

Em Educação infantil em três culturas: Japão, China e Estados Unidos, Tobin e colaboradores anunciam os dois objetivos perseguidos no estudo de culturas estrangeiras: além de transformar o exótico em familiar, trabalhar para tornar o familiar exótico. Esperavam que os participantes da pesquisa (professores, gestores e pais) encontrassem algo familiar, atrativo e útil nas instituiçôes estrangeiras, e que a leitura sobre a escola da própria cultura, ao lado das estrangeiras, encorajasse "um processo de desfamiliarização cultural, uma realização da arbitrariedade essencial e limite cultural de práticas e crenças vistas como certas.” (TOBIN et al., 2008, p. I9)

A pesquisa de Jensen não se caracteriza como um estudo de culturas estrangeiras, pois os filmes não foram mostrados com esse fim. No entanto, evidencia que o uso de filmes para desencadear reflexóes sobre compreensōes da prática pedagógica a partir de experiências contrastantes teve esse efeito de desfamiliarização cultural e gerou um número significativo de opinióes, crenças e lógicas, permitindo identificar tendências e padrôes de compreensão no que se refere a boas práticas pedagógicas da educaçáo infantil. Para Jensen (20I I, p. I43), o poder do método de gerar insights sobre entendimentos decorre, em parte, de sua forma estética, "o imediatismo e o poder do filme enquanto mídia", e, em parte, da "natu- 
reza exótica dos dois filmes que mostram a prática estrangeira”, no caso a Hungria e a Inglaterra. Embora o foco da pesquisa náo seja comparar as práticas em si, a utilização de filmes sobre práticas de outros países provoca uma discussão acerca dos contrastes percebidos entre os três países, o que acaba revelando o que é uma boa prática pedagógica para os observadores.

Outra característica que se evidencia em ambas as abordagens é o equilíbrio de poder entre o pesquisador e os participantes da pesquisa. $\mathrm{O}$ pesquisador tem menos poder e controle em relação aos métodos tradicionais da pesquisa qualitativa: não é ele quem elege os temas e elabora as questôes, mas a discussão no grupo focal disparada pelo conteúdo do filme que levanta as questóes e define os temas. Nesse sentido, há um empoderamento dos sujeitos participantes da pesquisa que emprestaram suas vozes para interpretação, avaliação e crítica.

\section{Notas}

I Analyse Lexicale par Contexte d'um Esemble de Segments de Texte

2 A esse respeito ver o Movimento de Reconceitualizaçáo da Educação Infantil (Reconceptualizing Early Childhood Education Movement - RECE) http://www.receinternational.org

3 Para maior informaçáa sobre os resultados da pesquisa como um todo consultar Care Work in Europe:Current Understandings and Future Directions (CAMERON; MOSS, 2007)

\section{Referências}

BANKS, Marcus. Dados visuais para pesquisa qualitativa. (Coleção Pesquisa Qualitativa). Porto Alegre: Artmed, 2009.

CAMERON, C.; MOSS, P. Care Work in Europe. Current understandings and future directions. Londres; Nova Iorque: Routledge, 2007.

CAMERON, C. Understandings of care work with young children: reflections on children's independence in a video observation study. Thomas Coram Research Unit, Institute of Education, University of London, 2007. Disponível em http://eprints.ioe. ac.uk/4823/I/Cameron2007Understandings.pdf. Acesso em 20.10.2013 
CORDEIRO, M. H.; HADDAD, L.; ANDRADE, D. B. S. F. Uma abordagem psicossocial ao estudo da docência na Educação Infantil: desafios conceituais e teórico-metodológicos. In: ENS, Romilda Teodora; VILLAS BÔAS, Lucia; NOVAES, Adelina. (Org.). Formação de professores: das políticas educativas à profissionalização docente. Ied. Curitiba; São Paulo: Editora Champagnat/PUCPRess; Fundação Carlos Chagas, 2016, p. 207-236.

HADDAD, L.; Profissionalismo na educação infantil: perspectivas internacionais. Revista de Educação Pública, v. 22, 2013, p. 34I-359.

HADDAD, L.; CORDEIRO, M. H. ; LO MONACO, G. As tarefas do professor de educação infantil em contexto de creche e pré-escola: buscando compreender tensóes e oposições. Educação \& Linguagem, v. I5, 2012, p. I34-I54.

HANSEN, H. K.; JENSEN, J. J. A Study of Understandings in Care and Pedagogical Practice: experiences using the Sophos Model in cross national studies. Londres: 2004 (Relatório de pesquisa, náo publicado).

JENSEN, J. J. A Study of Understandings in Care and Pedagogical Practice: experiences using the Sophos Model in cross national studies. Londres, 2004 (Relatório de pesquisa, não publicado).

JENSEN, J. J.; HADDAD, L. O programa de formação de pedagogos na Dinamarca: especialização em pedagogia da primeira infância. Poiésis - Revista do Programa de Pós-Graduação em Educação (Unisul), v. I2, 20I8, p. 9-3I.

JENSEN, J. J. "A Danish Perspective on Issues in Early Childhood Education and Care Policy.” In: MILLER, L. et.al. Sage Handbook of Early Childhood. London: Sage, 20I7, p. 7 I-86.

JENSEN, J. J. The Danish pedagogue education. In VANDENBROECK, M.; URBAN, M.; PEETERS, J. (Ed). Pathways to Professionalism in Early Childhood Education and Care. In: Hampshire: Routledge, 2016. p. I5-28.

Jensen, J. J. Hovedkroppe, porcelansdukker og mudderbørn. En diskussion af pædagogers forståelse af dansk daginstitutionspraksis. [Corpos de cabeça, bonecas de porcelana e crianças de barro. Uma discussão sobre a compreensão dos educadores sobre a prática de educação infantil dinamarquesa. Copenhagen, BUPL, 2019 Disponível em https:// bupl.dk/wp-content/uploads/2018/o2/publikationer-hovedkroppe-porcelaensdukkerog-mudderboern.pdf. Acesso em 20 de maio de 2019.

JENSEN, J. J. Understandings of Danish Pedagogical Practice. In: CAMERON, C.; MOSS, P. Social Pedagogy and Working with Children and Young People. Londres; Filadelfia: Jessica Kingsley, 20I I. p. I4I-I57. 
JENSEN, J. J. Compreensóes da prática em centros de educação infantil na Dinamarca, Inglaterra e Hungria. In: SOUZA NETO, João Clemente de; NASCIMENTO, Maria Letícia B. P. ; SAETA, Beatriz Regina P. (Org.). Infância: violência, instituições e políticas públicas. v. 2. São Paulo: Expressão e Arte, 2007. p. 97-I07.

Langsted, Ole. Looking at quality from the child's perspective. In: Moss, P. ; Pence, A. (Orgs.) Valuing Quality in Early Childhood Services. Londres: Paul Chapman Publishing, 1994. p. 28-42.

MILLER, L.; DALLI, C.; URBAN, M. (Org.). Early Childhood Grows Up: Towards a Critical Ecology of the Profession. Londres; Nova Iorque; Spring, 2012. (International Perspectives on Early Childhood Education and Development, 6).

TOBIN, Joseph; HSUEH Yeh; KARASAWA, Mayumi. Preschools in Three Cultures Revisited. Chicago: University of Chicago Press, 2009.

TOBIN, J. ; WU, D.Y.H; DAVIDSON, D. H. Educação infantil em três culturas: Japão, China e Estados Unidos. São Paulo, Phorte Editora, 2008.

TOBIN, Joseph; HSUEH, Yeh. The Poetics and Pleasures of Video Ethnography of Education. In: GOLDMAN, R. (Ed). Video Research in the Learning Sciences. NY: Lawrence Erlbaum Associates. 2007. p. 77-92

TOBIN, Joseph; DAVIDSON, Dana. The ethics of polyvocal ethnography: empowering vs. textualizing children and teachers. International Journal of Qualitative Studies in Education, 3:3, 27I - 283, I990. DOI: 10.1080/0951839900030305

TOBIN, J. J.; WU, D. Y. H.; DAVIDSON, D. H. Preschool in Three Cultures. New Haven and London: Yale University Press, I989.

Recebido em 30 mai. 2019 / Aprovado em 4 set. 2019 Para referenciar este texto:

HADDAD, L. O uso de filmes para obter compreensóes sobre a prática pedagógica em educação infantil: duas abordagens metodológicas. EccoS - Revista Científica, São Paulo, n. 50, eI40I6, jul./set. 2019. Disponível em: https://doi.org/I0.5585/EccoS. n50.14016. 